\title{
Pergeseran Bentuk Siluet Kostum Tari Jaipongan Tahun 1980-2010
}

\author{
Mira Marlianti, Acep Iwan Saidi, Achmad Haldani Destiarmand \\ Jurusan Seni Rupa - Institut Seni Budaya Indonesia (ISBI) Bandung \\ Jalan Buahbatu Nomor. 212 Bandung 40265 \\ Program Studi Magister Desain - Fakultas Seni Rupa dan Desain ITB
}

\begin{abstract}
This article is aimed at identifying the shift in silhouette of Jaipongan costume from its first appearance (in 1980) until thirty years later (2010). The silhouette of Jaipongan costume keeps changing at present, and is believed to become trends followed by other costume designers in different areas. Since it has never been studied by other researchers, the study result is expected to be the reference for future studiesthat focus on Jaipongan. The approach used in this study is aesthetics of form. The result shows that the aesthetics shift in silhouette of Jaipongan costume took place because the designers hadopportunities and freedom to be more expressive in designing Jaipongan dance costumes appropriate to current trends of the era and of the show. The shifts includesilhouette of blouse that entirely appears in silhouette fited and silhouette of skirt from slim line to fit and flare line. While the silhoutte cutting has shifted from amphora silhouette, hourglass silhouette, redingote silhouette toextra redingote silhouette.
\end{abstract}

Keywords: shift, silhouette, Jaipongan costume periode 1980-2010

\begin{abstract}
ABSTRAK
Tampilan kostum Jaipongan sejak awal kemunculannya hingga kini semakin bervariasi, sehingga memungkinkan terjadinya pergeseran dalam hal siluet kostumnya. Tulisan ini bertujuan mengidentifikasi pergeseran bentuk siluet kostum Jaipongan tahun 1980-2010 di wilayah Bandung. Persoalan ini penting dikaji karena kajian terhadap bentuk siluet kostum Jaipongan belum pernah dilakukan oleh peneliti lain dan kostum Jaipongan di Bandung disinyalir menjadi trend senter yang banyak ditiru para penata kostum di wilayah lainnya. Tahun 1980-2010 dipilih karena untuk melihat pergeseran bentuk siluet kostum Jaipongan dari awal kemunculannya hingga genap tiga puluh tahun 'keterkinian'-nya yang masih terus berkembang hingga kini. Pendekatan yang digunakan untuk kepentingan tersebut adalah estetika. Hasil kajian menunjukkan bahwa pergeseran bentuk siluet kostum Jaipongan terjadi karena bermunculanya kreativitas-kreativitas baru yang lebih bebas dan lebih ekspresif dalam hal perancangan desain kostum tari Jaipongan, sebagai upaya menyeimbangan akan tuntutan jaman dan tuntutan pertunjukan. Pergeseran tersebut meliputi siluet kostum atasan yang seluruhnya tampil dalam silhouette fited, dan bentuk siluet kostum bawahan yang berawal dari slim line menjadi fit and flare line. Adapun potongan silhouette diawali amphora silhouette, hourglass silhouette, redingote silhouette, dan diakhiri ekstra redingote silhouette.
\end{abstract}

Kata kunci: pergeseran, bentuk siluet, kostum Jaipongan rentang tahun 1980-2010 


\section{PENDAHULUAN}

Kostum Jaipongan merupakan salah satu elemen elemen penting dalam pertunjukan tari Jaipongan. Hal ini dikarenakan objek yang pertama kali tertangkap secara visual dan bisa langsung dinikmati oleh penikmatnya adalah kostum tari tersebut. Pada awal kemunculannya, kostum Jaipongan tampil sederhana sebagai cerminan kerakyatan dengan unsur-unsur budaya lokal yang masih sangat kental. Struktur dasar kostumnya memakai pola tradisional seperti sinjang Priangan, kebaya dengan aksesoris seperti selendang, ikat pinggang/beubeur, rangkaian bunga, anting, dan gelang. Pada awal tahun 80'an tampilan tersebut mengadopsi busana yang dikenakan para penari Ronggeng Banjidoran sebagai sumber gagas utamanya. Ronggeng Banjidoran adalah penari dan penyanyi perempuan profesional pada hiburan tradisional Banjidoran, sebuah pertunjukan tradisional tarian hiburan rakyat.

Sejalan dengan perkembangan penciptaan tata gerak tari Jaipongan yang semakin hari semakin interaktif dan dinamis, secara tidak langsung mengharuskan kostum Jaipongan mengalami perkembangan, yang tentu saja tidak bisa dilepaskan dari persoalan estetik karena kostum tari kehadirannya harus nilai tampak estetis. Saat ini, tampilan estetika kostum Jaipongan menjadi barometer kemajuan masyarakat pendukungnya. Penggunaan kostum Jaipongan bukan sekedar tuntutan akan perlindungan badaniah belaka tetapi lebih didominasi pula oleh tuntutan kepekaan estetik dan kreativitas artistik yang tinggi. Kostum Jaipongan telah berkembang ke arah yang fashionable dan modern dibandingkan pada masa awal kemunculannya. Ini terkait dengan sifat masyarakat sebagai penontonnya yang selalu menginginkan kebaruan dari kostum Jaipongan serta adanya pengaruh budaya industri dan budaya global terhadap seni Jaipongan.
Tampilan kostum Jaipongan yang semula mengakar kuat pada budaya Sunda bergeser ke arah yang lebih fashionable dan modern, sebagai upaya agar Jaipongan tetap eksis sesuai tuntutan jaman. Perkembangan tampilan kostum Jaipongan yang semakin variatif inilah yang menyebabkan lahirnya kostum-kostum yang bersifat kebaruan dalam genre tari Jaipongan. Perkembangan kostum Jaipongan tanpa disadari ternyata berdampak pada bergesernya bentuk siluet kostumnya itu sendiri. Bentuk siluet merupakan salah satu unsur yang diperlukan dalam membentuk suatu model kostum secara utuh, yakni berupa pembatasan akan struktur bentuk luar suatu desain atau silhouette. Bentuk siluet kostum Jaipongan akhirnya semakin variatif sebagai dampak dari perkembangan kostum Jaipongan yang terus menggeliat.

Fenomena pergeseran bentuk siluet kostum Jaipongan di atas menarik untuk dikaji karena dua hal. Pertama, kajian terhadap bentuk siluet kostum Jaipongan belum pernah dilakukan oleh peneliti lain, sehingga diharapkan tulisan ini dapat melengkapi sudut pandang keilmuan akan penelitian-penelitian kajian Jaipongan yang telah dilakukan terdahulu; Kedua, kostum Jaipongan di Bandung disinyalir menjadi trend setter yang banyak ditiru para penata kostum di wilayah lainnya. Tahun 19802010 dipilih karena untuk melihat pergeseran bentuk siluet kostum Jaipongan dari awal kemunculannya hingga genap tiga puluh tahun 'keterkinian' bentuk siluet kostum Jaipongan yang masih berkembang hingga kini. Tujuan kajian ini adalah mengidentifikasi pergeseran bentuk siluet kostum Jaipongan sebagai upaya pendataan perkembangan kostum Jaipongan yang merupakan bagian dari karya seni budaya Sunda.

\section{METODE}

Kajian ini menggunakan metode este- 
tik, khususnya dalam menganalisis bentuk siluet kostum Jaipongan. Metode estetik yang dimaksud berdasarkan pada teori estetika Parker dan Djelantik. Sebagaimana dikutip Kartika (2007: 63), Parker memandang keindahan sebagai suatu kwalita dari benda-benda yang masih mempunyai sisi menyenangkan dan tetap mempunyai nilai estetik sehingga dapat dikatakan indah. Terlebih untuk karya seni yang merupakan hasil ciptakan manusia yang berkaitan dengan nilai estetik adalah bentuk estetik (aesthetic form) dari benda yang bersangkutan. Sebagai karya seni, objek material kajian ini tentu termasuk ranah yang dipahami oleh Parker sebagai kualita keindahan. Sementara itu Djelantik (1990: 14) menyatakan bahwa semua benda atau peristiwa kesenian mengandung tiga aspek mendasar, yakni: (1) Wujud atau 'rupa'/'appearance', (2) Bobot atau 'isi' 'content, substance', dan (3) Penampilan atau penyajian 'presentation'. Oleh karena fokus kajian ini hanya pada ranah bentuk, maka telaah pada objek material sebatas pada estetika wujud, yakni bentuk (form) siluet kostum Jaipongan. Siluet kostum tersebut terbentuk dari unsurunsur desain yang paling mendasar, yakni bentuk sebagai unsur dasar garis terluar dari tampilan kostum Jaipongan.

Bentuk siluet kostum Jaipongan selanjutnya diidentifikasi berdasarkan estetika struktur (mengesampingkan makna) yang mana terfokus pada kualita pembentuk tanda visual yang mewujud menjadi suatu tampilan kostum Jaipongan. Kualita estetik yang dimaksudkan adalah unsur desain berupa garis pembentuk sebuah tampilan siluet kostum Jaipongan.

Telaah fokus wujud siluet kostum Jaipongan yang dianalisis disini adalah mengenai salah satu dari elemen desain dalam fashion yakni hanya berupa bentuk dan siluet. Bentuk (silhouette/shape) dari kostum menurut Stone (2000: 9) adalah semua garis luar atau kontur. Berdasarkan pemahaman ini maka hal yang dianalisis adalah bentuk/ shape atau form terluar dari kostum Jaipongan secara utuh, yakni terdiri atas bentuk silhouette kostum atasan dan bentuk silhouette kostum bawahan. Penggabungan bentuk silhouette kostum atasan dan bentuk silhouette kostum bawahan menghasilkan analisis bentuk potongan silhouette kostumnya. Hasil analisis akan menjadi pembuktian adanya pergeseran bentuk siluet kostum yang ada di wilayah Bandung di tahun 1980-2010.

\section{HASIL DAN PEMBAHASAN Kostum dan Bentuk Silhoutte}

Istilah busana atau kostum memiliki banyak pengertian. Dalam buku Rias dan Busana Tari Sunda, Caturwati (1997: 29) menjelaskan bahwa menurut Onong Nugraha terdapat berbagai pendapat mengenai pengertian dari kostum, namun dapat disimpulkan bahwa yang dimaksud dengan busana adalah segala yang dikenakan seseorang yang terdiri dari pakaian dan perlengkapannya (accessories), dan identik dengan kata kostum. Istilah kostum, busana atau pakaian pada dasarnya merupakan padanan kata yang sama atau identik, namun penggunaan istilah kostum dalam tulisan ini dipandang lebih tepat karena apa yang dikenakan oleh pemakainnya tidak bersifat umum dan tidak begitu lazim digunakan dalam kehidupan sehari-hari. Kostum juga memiliki arti khusus serta mengandung penekananan muatan nilai estetis yang lebih dominan. Sebagaimana dicatat oleh Budi Setiyono bahwa ketika fungsi pakaian sebagai penutup tubuh tak lagi dominan, melainkan digantikan citracitra simbolik dan estetis, ini berarti membicarakan soal kostum. la menjadi bagian penting dari performance karena menjadikan individu atau suasana tertransformasikan ke dalam individu atau suasana yang berbeda dari keadaan sehari-hari (Agus Bing, dkk., 2009: 29). 
Kehadiran kostum membuat sebuah pertunjukan kian hidup dan meneguhkan citra spesifik. Terlebih pada era sekarang kostum bukan sekedar pelindung tubuh belaka atau hanya sebatas pendukung, melainkan kemelekatannya pada tubuh dan vitalitas fungsi kostum itu sendiri dapat menentukan keutuhan atau berhasil tidaknya sebuah pertunjukan. Senada dengan itu, I Nyoman Sura mengungkapkan bahwa kostum (pada kasus tari) harus sesuai dengan ide penata tari, kemudian disesuaikan dengan karakter tari: keras atau lembut. Kostum benar-benar diciptakan secara tepat sesuai dengan koreografi, tempat pertunjukan, dan lighting. Kostum dan rias akan merepresentasikan karya-karya itu sendiri, bukan sekadar pembungkus tubuh (Agus Bing, dkk., 2009: 33).

Setiap kostum memiliki bentuk silhouette. Perwujudan silhouette itu sendiri tidak lepas dari persoalan desain yang menurut Riyanto (2003: 28) memiliki unsur-unsur atau elemen desain, yakni: (1) garis, (2) arah, (3) bentuk, (4) ukuran, (5) warna, (6) nilai dan (7) tekstur. Oleh karenanya, kajian terhadap silhouette kostum akan bersinggungan dengan unsur desain berupa garis yang membentuk suatu form dan shape (per- wujudan) sebagaimana dinyatakan Riyanto (2003: 28), bahwa “Garis merupakan penghubung dua buah titik. Di dalam suatu desain busana garis sebagai salah satu unsur yang diperlukan dan mempengaruhi suatu model busana, dimana garis sebagai garis luar dari model busana yang disebut siluet (Silhouette)".

Suryahadi (1987: 5) juga menegaskan, bahwa line atau disebut garis merupakan susunan titik-titik atau tanda yang memanjang yang menghubungkan antara dua bagian. Garis merupakan efek yang dibuat oleh batas dari suatu obyek dimana sebenarnya tidak ada garis nyata pada obyek tersebut. Garis dapat menuntun mata ke arah garis itu berakhir, dan membagi daerah yang dilewatinya, membatasi bentuk strukturnya atau silhouette.

Kaitannya dengan fashion, Takamura (1993:18-20) menuliskan bahwa "silhouette line is the counter of a garment. Other name: form". Menurutnya silhouette line terdiri dari delapan belas macam kategori tampilan, yakni: Arrow line, Anple line, 8 line, X line, H line, Sack line, A line, Sheath line, Straight line, Spindle line, Slim line, Soft conscious line (soft body-conscious line), Tulip line, Fit and flare line, Princess line, Pencil line, Mermaid line, and Y line.

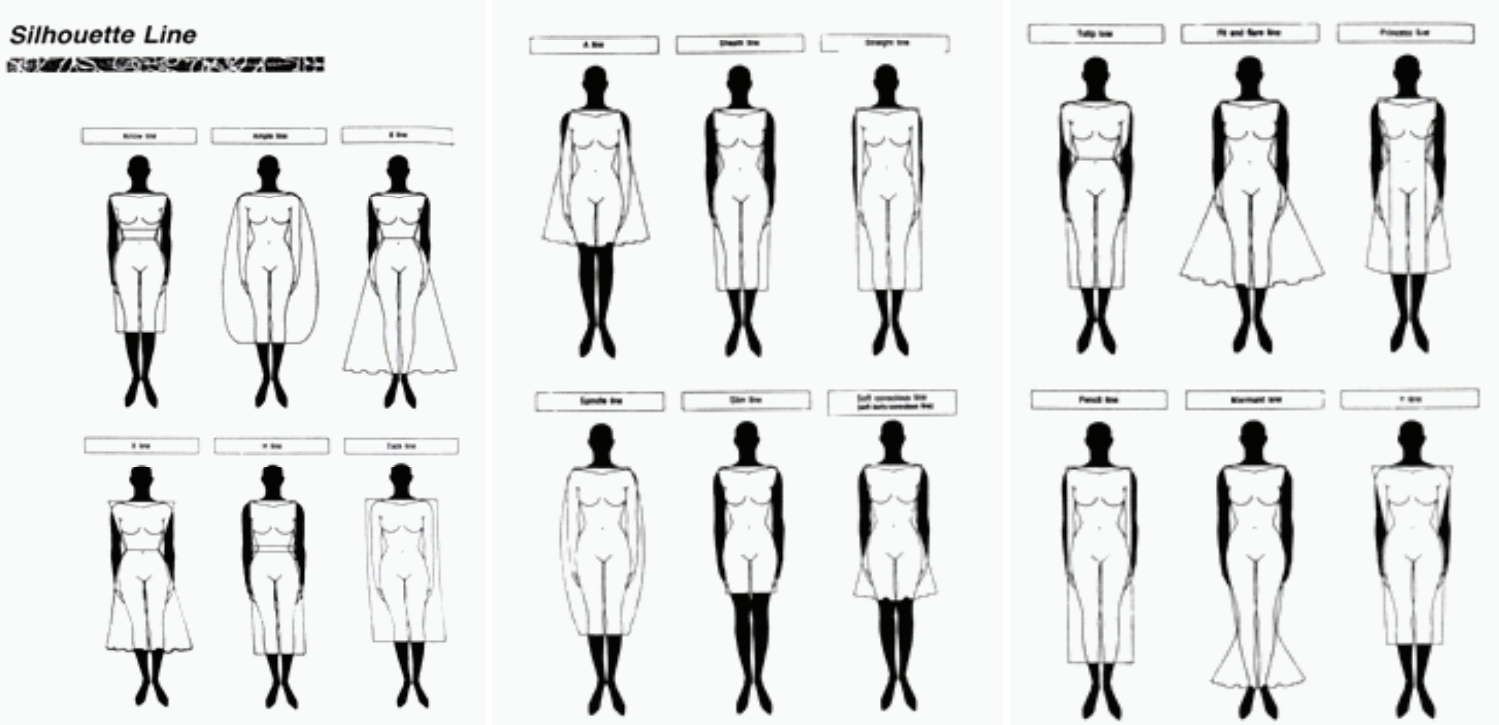

Gambar 1. Bentuk Struktur Garis Siluet Busana (Silhouettes Dress Line)

(Sumber: Takamura, 1993: 18-20) 
Sementara itu Esmod (1995: 58-59), membagi siluet (the silhouette) menjadi empat kategori besar, yakni siluet lurus (the straight silhouette), siluet bulat (the round silhouette), siluet pas pinggang (the fitted silhouette) dan siluet trapezium (the trapeze silhouette).

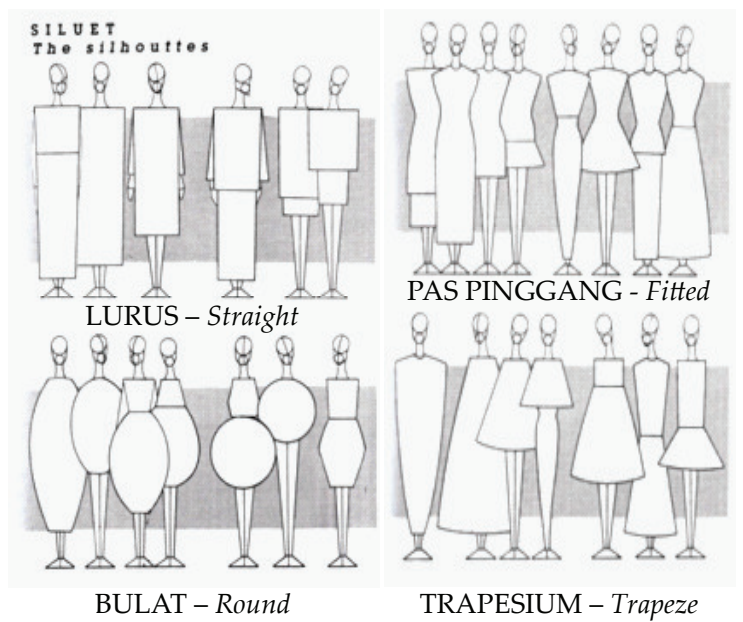

Gambar 2. Bentuk Struktur Garis Siluet Busana (Silhouettes Dress Line)

(Sumber: Esmod, 1995:58-59)

Berdasarkan dua sumber tersebut, analisis bentuk struktur garis siluet kostum Jaipongan dalam tulisan ini diadobsi berdasarkan pengkategorian dari dua sumber tersebut (pengkategorian silhouette dari kedua sumber tersebut bersifat saling melengkapi). Yang mana penganalisian dari bentuk silhouette line atasan menggunakan analisis pengkategorian dari sumber yang dikeluarkan oleh Esmod, sedangkan untuk menganalisi bentuk silhouette line bawahan dan analisis potongan silhouette menggunakan pengkategorian dari sumber Takamura.

\section{Bentuk Siluet Kostum Jaipongan}

Bentuk siluet kostum Jaipongan yang dikaji dalam tulisan ini adalah tampilan bentuk silhouette kostum atasan, bentuk silhouette kostum bawahan, serta bentuk potongan silhouette kostum Jaipongan secara utuh yang teridentifikasi keberadaannya dalam rentang waktu tahun 1980-2010.
Tampilan kostum Jaipongan yang dianalisis terhimpun dari data visual berupa dokumentasi foto yang dipilih random namun memiliki keterangan waktu yang dipandang dapat mewakili periode tertentu.

\section{Tahun 1980 - 1997}

Pada awal kemunculannya, seluruh kostum Jaipongan berkiblat pada tampilan kostum Jaipongan yang dikenakan penari kelompok Gugum Gumbira. Dimana tampilannya cukup sederhana sebagai cerminan kerakyatan dengan unsur-unsur budaya lokal yang masih sangat kental. Dasarnya struktur kostumnya memakai pola tradisional seperti sinjang Priangan, kebaya dan selendang. Saat itu tampilan tersebut mengadopsi busana yang dikenakan para penari atau Ronggeng Banjidoran sebagai sumber gagas utamanya. Tentang tampilan ini, Mulyana (2009: 161) menyatakan bahwa kostum penari wanita tari Jaipongan pada awalnya merupakan pengembangan dari busana pesinden Kliningan Bajidoran, baik dari sisi bentuk maupun warnanya. Gugum kemudian memasukkan motif kebaya dan sinjang Priangan, serta aksen melalui pengayaan ornamen, sehingga kostum Jaipongan memiliki karakter yang sesuai dengan jiwa tarian dan memberikan jati diri tari yaitu jati diri Kasundaan.

Pengembangan yang dilakukan Gugum Gumbira pada tari Jaipongan menurut Wardojo (1986: 30) masih memperlihatkan lokal genius, yaitu adanya unsur-unsur atau ciri-ciri tradisional yang mampu bertahan dan bahkan memiliki kemampuan untuk mengakomodasi unsur-unsur budaya dari luar serta mengintegrasikannya dalam kebudayaan asli.

Dapat dikatakan bahwa tata kostum Jaipongan era ini bernilai estetika tradisional, yang mana secara garis besar memiliki dasar konstruksi kostum atasan dan bawahan yang hampir sama tiap tahunnya, sehingga menghasilkan bentuk siluet 
kostum yang sama pula pada tiap varian tampilannya. Seluruh tampilan kostum tari Jaipongan tersusun atas bentuk silhouette line atasan dan bentuk silhouette line bawahan yang sama, sehingga menghasilkan bentuk potongan silhouette yang sama pula.

Bentuk silhouette line kostum atasan berupa silhouette fited terbentuk dari konstruksi siluet kebaya Sunda yang pas pinggang dan mengikuti bentuk tubuh (body fit), terlebih dengan penggunaan kupnat pada bagian depan dan belakang bagian pinggang yang memberikan kerampingan pada bagian pinggang. Adapun silhouette line kostum bawahan tampil slim line merupakan efek dari penggunaan sinjang Priangan yang melilit pas badan (body fit). Secara keseluruhan potongan silhouette kostum tergolong sebagai amphora silhouette yaitu siluet kostum dengan kesan konstruksi bagian atas pas membentuk badan, kecil di pinggang, pas pinggul dan konstruksi bagian rok mengecil ke bawah seperti halnya rok model pensil.

\section{Tahun 1998}

Pada era ini pembangunan di segala bidang sedang digalakkan termasuk bidang kesenian. Hal ini nampak dengan adanya perkembangan di sektor kebudayaan dan kesenian yang cukup gencar. Salah satunya adalah adanya kunjungan pagelaran-pagelaran seni dan budaya ke luar negeri, maupun sebaliknya. Fenomena ini membuat para pelaku seni dan penggiat tari Sunda terus berupaya meningkatkan kualitas tampilan seni dan budayanya. Terlebih saat itu Jaipongan berhasil mencuri perhatian masyarakat dari berbagai kalangan termasuk kalangan elite politik. Tari Jaipongan di masa ini banyak dipagelarkan berdasarkan pesanan partai politik tertentu, bahkan mulai tahun 1998 pihak Gugum Gumbira banyak diminta untuk mengadakan perhelatan Jaipongan dengan beberapa persyaratan khusus menyangkut tampilan kostum Jaipongannya. Persyaratannya tersebut acap kali berupa peringatan mengenai kostum tari Jaipongan tidak boleh tampil seksi yang memperlihatkan bagian betis dan bagian atas payudara.

Berdasarkan fakta bahwa perkembangan Jaipongan semakin meningkat serta semakin banyaknya permintaan-permintaan pagelaran yang menginginkan bentukan tampilan kostum Jaipongan yang berbeda dalam berbagai event pertunjukannya, maka berdasarkan saran-saran dari beberapa rekan penggiat seni lainnya, Gugum mencoba membuat kostum Jaipongan khusus dalam arti kostum

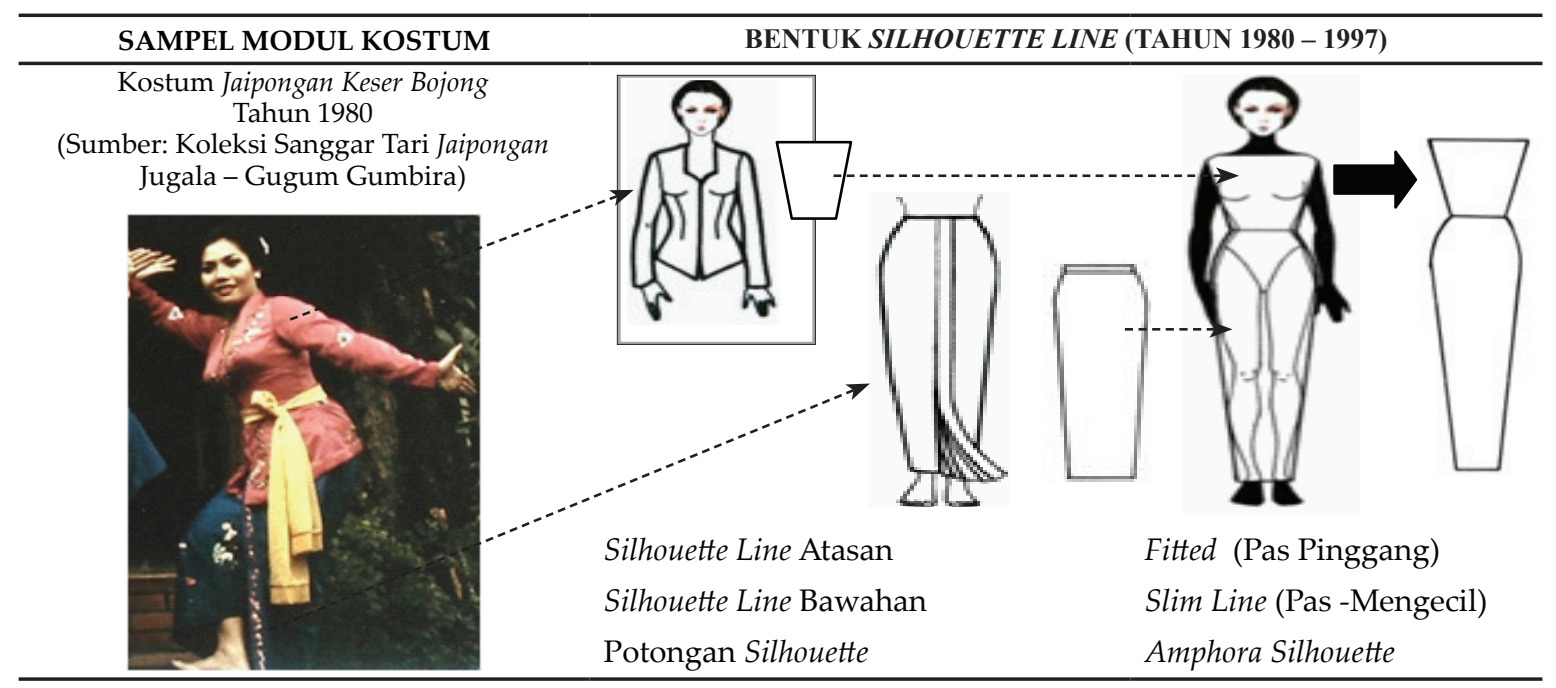

Gambar 3. Silhouette Line Kostum Tari Jaipongan (1980) - Tari Jaipongan Rendeng bojong

(Sumber foto: Ajie - Sanggar Tari Jugala/Gugum Gumbira, 1980. Ilustrasi: Rekonstruksi Penulis, 2013) 
Jaipongan yang baru secara desain maupun bentuk. Penata kostum Jaipongan yang memberikan andil besar akan kemunculan warna baru dalam tampilan kostum Jaipongan Gugum Gumbira pada tahun 1998 adalah Adjat Sudrajat dan Miya Rukmiyana yang berhasil membuat kostum tari Rawayan salah satu karya Gugum Gumbira.

Tampilan kostum Tari Rawayan inilah yang akhirnya menjadi tonggak pendobrak akan tampilan kebaruan dari kostum Jaipongan. Kostum Jaipongan Rawayan memberi jalan atau peluang besar bagi kreatorkreator penata kostum Jaipongan di wilayah Bandung khususnya, untuk mulai saling berlomba menuangkan kreativitasnya dalam membuat tampilan kostum Jaipongan yang baru yang berbeda dari sebelumnya.

Rawayan adalah 'cukang' (jembatan gantung) terbuat dari kayu atau bambu, yang jika diinjak akan bergoyang. Filosofi tarian ini berkaitan dengan fenomena budaya yang dalam gambaran tariannya bermuatan upaya untuk menjembatani tampilan peralihan dari era tradisional ke era kreasi baru (modern). Berdasarkan wawancara penulis dengan Miya Rumiyana (2012) dipaparkan bahwa tata kostum tari Rawayan ini adalah kostum tari Sunda standar berupa kebaya lengan panjang serta samping/sinjang (rok panjang bawahan). Untuk menyikapi gerakan tertentu seperti gerakan menendang di dalam samping/sinjang digunakan celana panjang dengan pertimbangan jika mengenakan samping/sinjang saja tidak etis ketika terangkat nampak betis dan paha. Kesan atau aksen kebaya lengan panjang yang digunakan berupa baju senam lengan panjang body size yang dikenakan di dalam, sedangkan baju luarnya berupa blouse memakai draperi. Kesan samping berupa rok panjang dengan aplikasi wiron/dodot, belahan depan dan draperi. Kesan celana panjang dalaman berupa celana tayet yang body size. Keberadaan celana ini untuk memenuhi ke- butuhan etika saja. Bahan kostum Rawayan ini dipilah yang lembut berkesan anggun, jatuh atau langsai, tidak mengambang atau melayang. Adapun pemilihan warna biru yang cenderung royal blue adalah upaya mengejar atau mendekati warna biru nila dari iket kepala masyarakat Baduy sebagai simbolisasi kesan buhun atau kerakyatan.

Berdasarkan tampilan kostum Rawayan (sebagai perwakilan dari kostum era tahun 1997) tersebut dapat dinyatakan bahwa tampilannya cenderung semi modern. Misalnya, penggunaan kebaya Sunda, sinjang lilit, bentuk dodot sinjang tradisional, pemakaian bunga melati (mangle) pada sanggul sebagai tampilan tradisi digantikan dengan penggunaan tayet/baju senam yang dilengkapi rompi berdraperi, rok A-line dengan bentuk dodot yang berbeda bentuk dan cara pemakaiannya. Dan penggunaan dari ikat pinggang logam, aksesoris sanggul berupa kembang goyang berbentuk daun awi (bambu), serta hiasan-hiasan (trimming) perak pada era sebelumnya tidak ada, maka dengan demikan penggunaannya pada era ini secara keseluruhan memberikan kesan estetika yang semi modern (tradisional-moderen).

Kostum Rawayan tampil bentuk silhouette line atasannya adalah fitted, dan bentuk silhouette line bawahan adalah fit and flare line (tampilan konstruksi siluet kostum yang pas pinggang dengan bagian rok sinjangnya A-line, lebar rok bagian bawahnya sedikit melebar). Kombinasi konstruksi siluet fitted dan fit and flare line menghasilkan proporsi potongan silhouette: hourglass silhouette yakni siluet kostum yang kecil di pinggang dan agak sedikit melebar di bagian rok ke bawah. Hal ini dikarenakan penggunaan rok sinjang yang berupa rok A-line atau rok dengan konstruksi $1 / 4$ lingkaran (rok $1 / 4$ klok).

Gambar silhouette line kostum Jaipongan Rawayan (tahun 1998) dapat dilihat pada gambar 6 . 


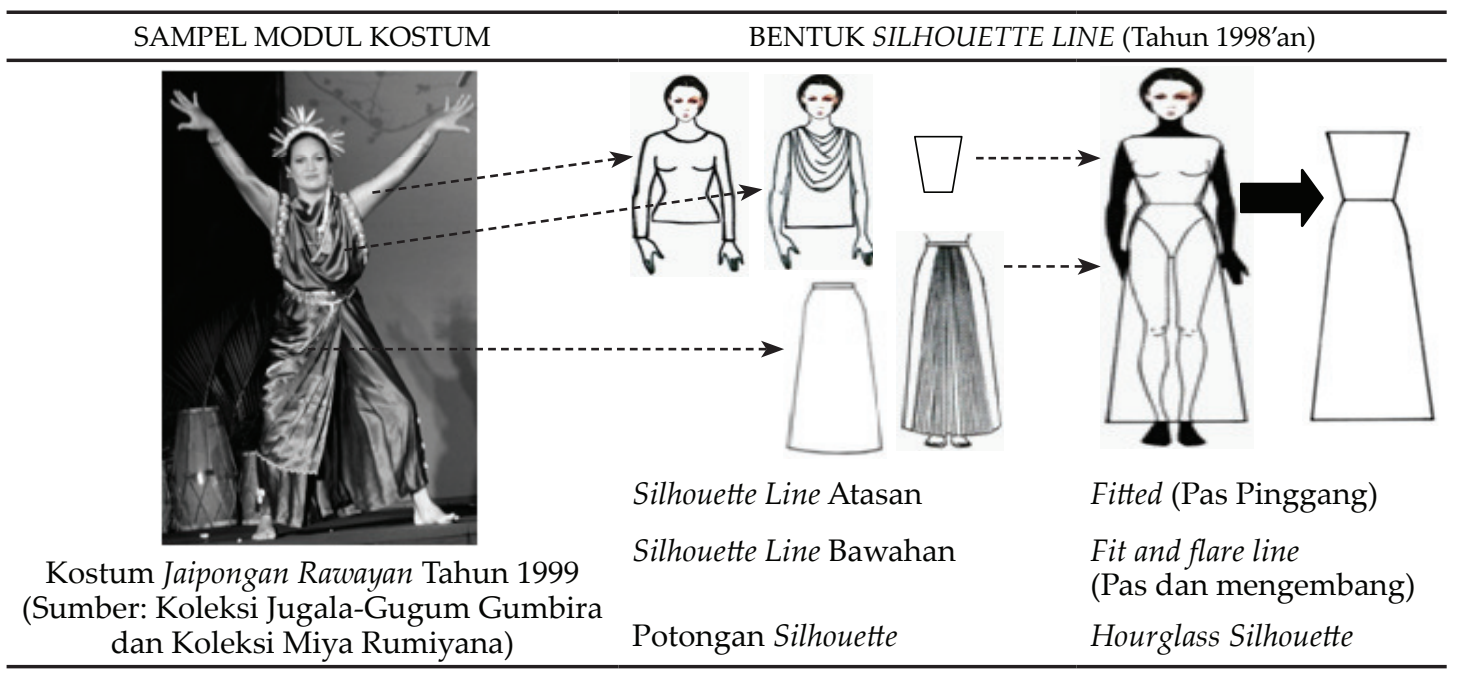

Gambar 6. Silhouette Line Kostum Jaipongan Rawayan (Tahun 1999)

(Sumber Foto: Koleksi Jugala-Gugum Gumbira dan Koleksi Miya Rumiyana.

Ilustrasi: Rekonstruksi Penulis, 2013)

\section{Tahun 2000 - 2010}

Fenomena berkembang dan berubahnya tampilan kostum Jaipongan pada era ini salah satunya dipicu oleh adanya himbauan tanggal 5 Februari 2008 yang datang dari Bapak Ahmad Heryawan (Gubernur Jawa Barat), yang meminta agar tarian Jaipongan diperhalus lagi dalam gerakannya (3G: Goyang, Gitek, Geol) serta dipersopan dari sisi 'kostum' yang dinilainya terlalu terbuka. Penari perempuannya diharapkan menggunakan kostum lebih tertutup, seperti menggunakan kebaya yang tidak mempelihatkan bagian ketiak, bagian atas payudara, bahu dan kaki.

Sebagai langkah revitalisasi kostum Jaipongan atas himbauan tersebut, maka kostum tari Jaipongan dibuat berupa penggunaan kebaya berbahan tidak transparan dilengkapi luaran berupa apok dan rok sinjang panjang dilengkapi tutup rasa atau kombinasi dari tayet ditambah luaran berupa apok dengan rok sinjang panjang yang juga dilengkapi tutup rasa. Pada era ini tampilan kostum Jaipongan yang biasanya tampak sederhana dan dan berkesan kerakyatan, berubah wujud menjadi tampak sangat glamor dan modern. Hal ini terlihat dari penggunaan kain-kain modern (seperti brocade, satin, sifon dll) yang semakin beragam, payet-payet yang hampir menghiasi seluruh bagian kostum, berbagai macam trimming (aplikasi hiasan) yang diterapkan, penggunaan warna yang lebih banyak sehingga semakin menyemarakan tampilannya, penggunaan akseoris berupa gelang, anting dan hiasan sanggul yang pada era ini umumnya menggunakan bunga-bungaan dan hiasan ornamen ceplok yang dirangkai dari manik-manik dan full payet.

Tampilan bentuk siluet kostum pada era ini berbagi atas bentuk siluet atasan yang masih fitted (pas badan/body fit), namun menggunaan rok sinjang yang tidak lagi berbentuk siluet slim, melainkan sudah berupa rok mengembang (flare) dengan struktur bentuk siluet yang lebih dibuat bebas bergerak. Tampilan kostum bawahan pada tahun ini terkonstruksi lebih lebar dan bebas dari keadaan ketat di bagian pinggul dan paha dengan pertimbangan agar lebih menunjang keleluasaan bergerak atau menari. Selain itu pada masa ini dalam tampil- 
an berkostum tarinya sudah menggunakan pula tutup rasa berupa kain penutup, selendang, pleats atau dodot yang bertujuan menyamarkan atau meng-cover bagian-bagian yang dianggap erotis pada saat melakukan pergerakan tari.

Pada tahun 2000-2010, kostum Jaipongan didominasi oleh bentuk silhouette line atasan maupun silhouette line bawahan yang sama. Bentuk silhouette line atasan tergolong siluet fitted (bentukan dari konstruksi kebaya, apok atau tayet yang body fit sengaja dibuat sangat anatomis mengikuti bentuk tubuh penari. Bentuk silhouette line bawahan adalah fit and flare line (bentukan dari konstruksi siluet rok yang pas pinggang kemudian melebar pada bagian bawahnya).

Tingkat kelebaran bagian bawah rok pada periode ini memiliki ukuran yang bervariasi yaitu mulai sedikit melebar, lebar hingga sangat lebar. Ukuran lebar bawah rok yang 'sedikit melebar' dikategorikan sebagai potongan siluet hourglass silhouette (dominasi kemunculan pada tahun 20022006). Potongan siluet ini merupakan per- panjangan dari potongan siluet dari akhir periode sebelumnya dimana potongan siluet hourglass silhouette umumnya terbentuk dari konstruksi bentukan rok 1/4 lingkaran atau rok $1 / 4$ klok. Ukuran lebar bawah rok yang 'lebar' dikategorikan sebagai potongan siluet redingote silhouette (dominasi kemunculan mulai pertengahan tahun 20052010). Potongan siluet ini terbentuk dari konstruksi bentukan rok $1 / 2$ lingkaran atau rok $1 / 2$ klok. Adapun ukuran lebar rok yang 'sangat lebar' dikategorikan sebagai potongan siluet kostum ekstra redingote silhouette (dominasi kemunculan pada akhir tahun 2008-2010). Potongan siluet ekstra redingote silhouette ini merupakan bentukan dari konstruksi bentukan rok lingkaran penuh atau rok klok.

Berdasarkan analisis di atas disimpulkan tahun 2000-2010 didominasi oleh tampilan bentuk silhouette line atasan dan bentuk silhouette line bawahan yang sejenis, namun bentuk potongan silhouettenya berbeda. Data visual bentuk silhouette kostum Jaipongan yang mewakili era 2000 - 2010 dapat dilihat pada gambar 7, 8, dan 9 .

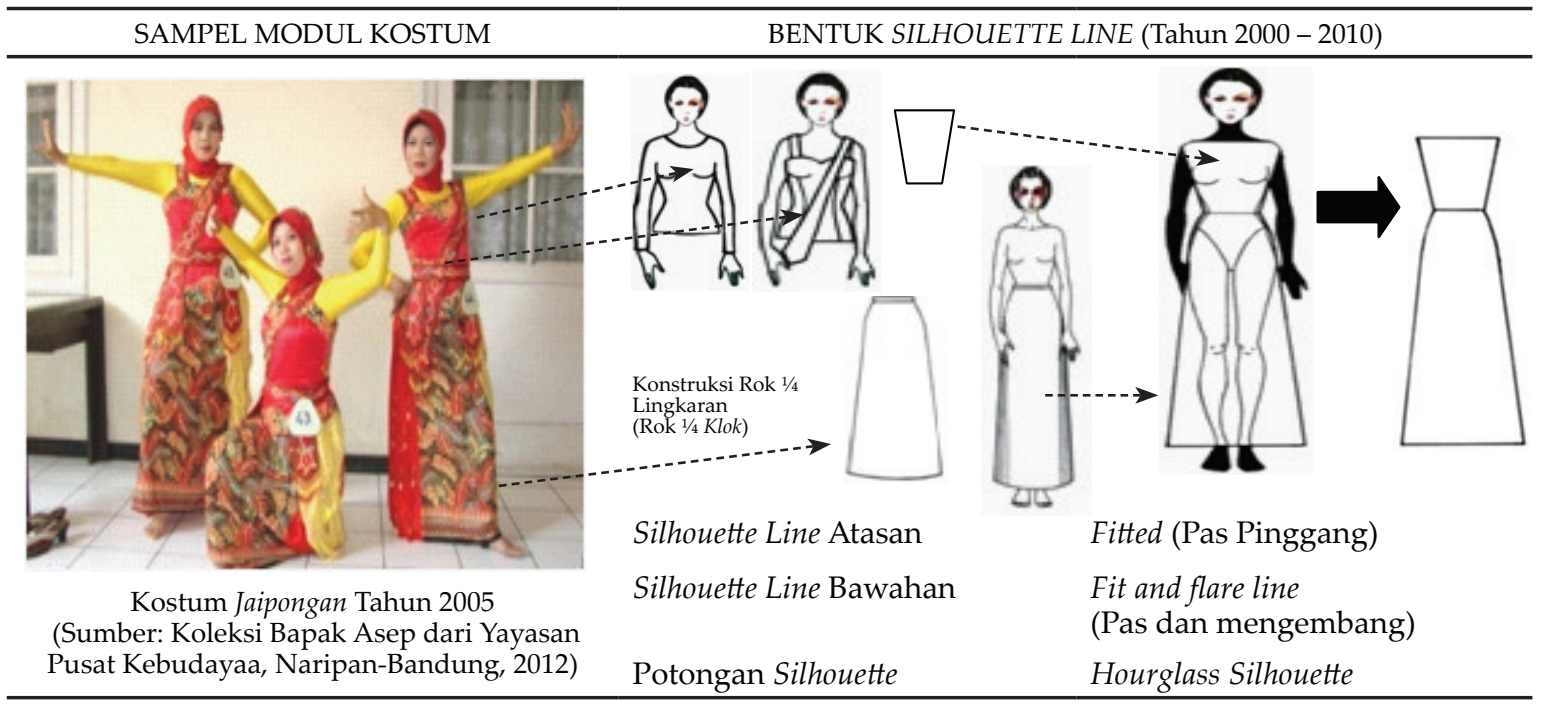

Gambar 7. Bentuk Silhouette Kostum Jaipongan Pada Tahun 2005 (Sumber Foto: Koleksi Bapak Asep dari Yayasan Pusat Kebudayaan, Naripan-Bandung, 2012 Ilustrasi: Rekonstruksi Penulis, 2012) 


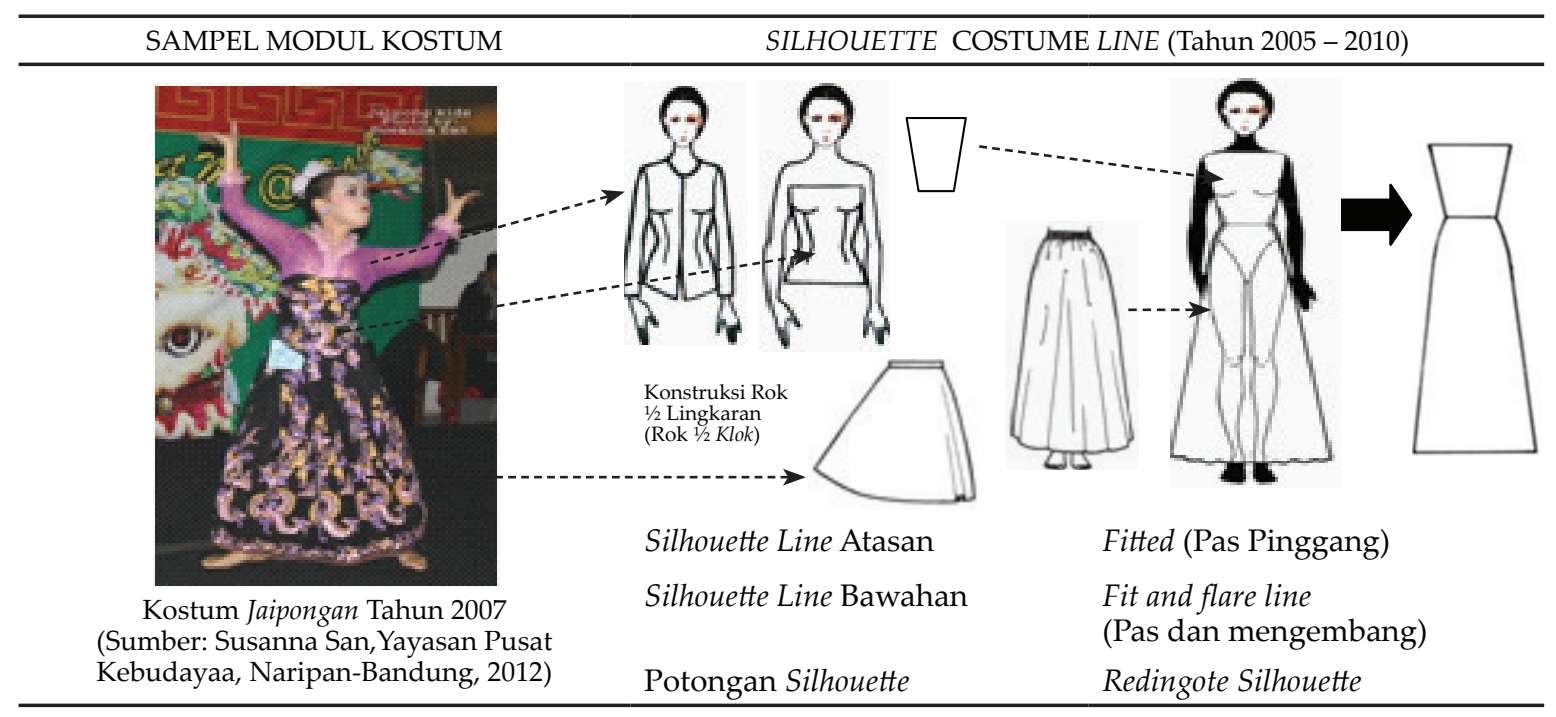

Gambar 8. Bentuk Silhouette Kostum Jaipongan Pada Tahun 2005-2010

(Sumber Foto: Koleksi Susanna San, Yayasan Pusat Kebudayaan, Naripan-Bandung, 2011. Ilustrasi: Rekonstruksi Penulis, 2012)

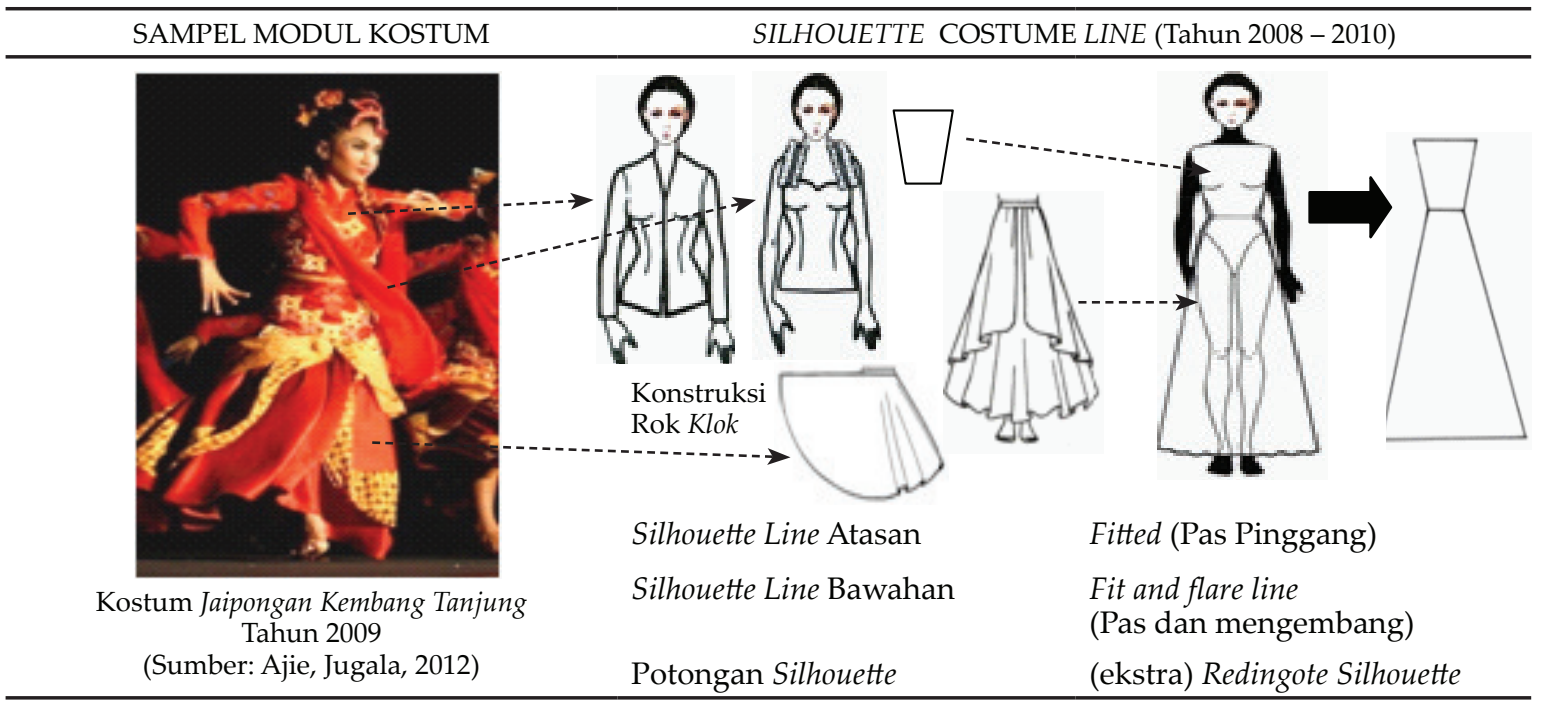

Gambar 9. Bentuk Silhouette Kostum Jaipongan Pada Tahun 2008-2010

(Sumber Foto: Koleksi Ajie, Jugala-Gugum Gumbira, 2012. Ilustrasi: Rekonstruksi Penulis, 2012)

Berdasarkan paparan tersebut, maka dapat dipetakan pergeseran estetika dari bentuk silhouette line kostum Jaipongan tahun 1980 -2010 seperti dapat dilihat pada gambar 10 .

\section{SIMPULAN}

Sejak kelahirannya di tahun 1980 hingga perkembangan kekiniannya di tahun 2010 tampilan tata kostum Jaipongan yang ada di Bandung pada dasarnya merupakan potret kebudayaan berpakaian masyarakat Sunda khususnya diperuntukan bagi kebutuhan seni tari yang menitikberatkan pada pengawetan seni tradisi yang didominasi oleh faktor estetik sesuai tuntutan jaman (modernisasi) dan tuntutan tata gerak tarinya. Hadirnya industri budaya dan pengaruh budaya global membuat tampilan kostum Jaipongan yang semula mengakar kuat pada budaya Sunda berubah ke arah yang lebih fashionable dan modern. Hal ini merupakan 


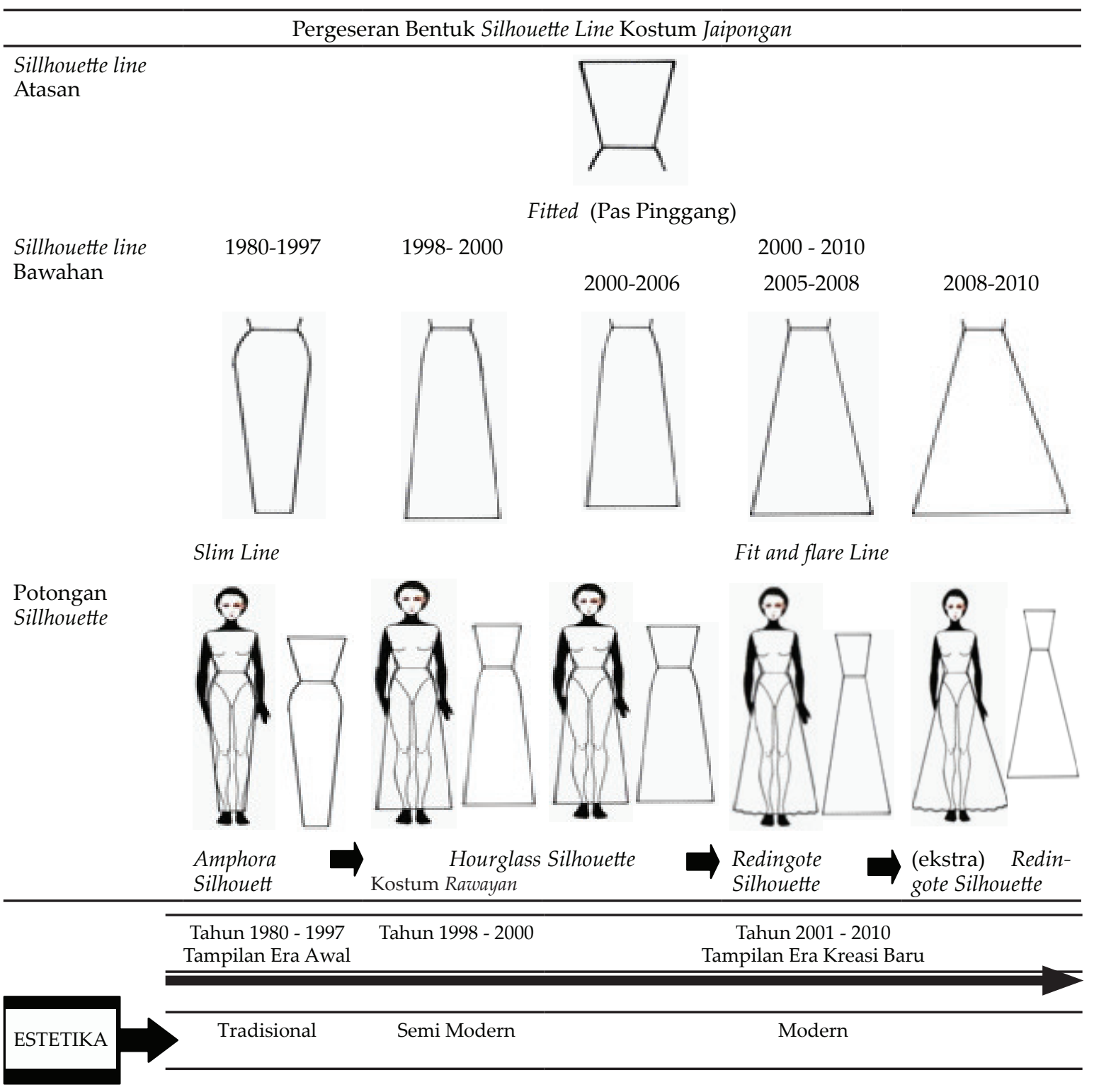

Gambar 10. Peta Pergeseran Estetika dan Bentuk Silhouette Line Kostum Jaipongan Tahun 1980 Hingga 2010 di Bandung

upaya para kreatornya agar kostum Jaipongan dapat tetap eksis dalam kehidupan masa kini yang selaras dengan tuntutan jaman.

Tampilan kostum Jaipongan pada masa kini terbentuk tidak secara instan tetapi melalui suatu proses panjang terkait berbagai faktor seperti ekonomi, budaya, agama, politik, dan lain sebagainya. Perkembangan kostum Jaipongan tersebut menyebabkan terjadinya pergeseran dalam bentuk siluet kostumnya pada tiap masa pergeserannya.

Pada awal kemunculannya (1980-1997) tampilan kostum Jaipongan cukup sederhana sebagai cerminan kerakyatan, serta penggunaan elemen kostum yang yang syarat dengan unsur-unsur budaya lokal yang masih sangat kental, misalnya penggunaan dari struktur dasar kostum berupa kebaya Sunda sebagai atasan dan memakai pola tradisional seperti sinjang Priangan sebagai kostum bawahannya, selain itu selendang, sanggul jucung ataupun sanggul Sunda kerap digunakan bersama dengan hiasan bunga melati (mangle). Tam- 
pilan kostum Jaipongan era ini benar-benar mengadopsi busana tradisional yang biasa dikenakan para penari atau Ronggeng Banjidoran. Hasil analisa bentuk silhouette line kostum pada era ini yang hanya terkonstruksi atas satu varian bentuk siluet kostum saja. Bentuk silhouette line kostum atasan berupa kebaya Sunda yang seluruhnya tampil dalam silhouette fited, sedangkan kostum bawahannya berupa penggunaan rok sinjang yang terkonstruksi membentuk silhouette line slim.

Pada era tahun 1998-2000, muncul kostum Jaipongan Rawayan yang menjembatani tampilan peralihan dari era tradisional ke era kreasi baru (modern). Pada tampilannya, kebaya Sunda yang biasanya dikenakan digantikan oleh baju senam lengan panjang body size yang dilengkapi dengan baju luarnya berupa blouse kutung yang bergaris leher draperi, bentuk dan peletakan dodot tradisi Priyangan dimodifikasi menjadi kain sinjang berupa rok panjang dengan aplikasi wiron/dodot, belahan depan dan draperi. Busana tambahan lainnya yang digunakan adalah kesan celana panjang dalaman berupa celana tayet yang body size. Serta penggunaan warna yang biasanya tergolong tabrak warna pada tampilan kostum Rawayan dibuat monokromatis yakni mengunakan pemilihan warna biru yang cenderung royal blue sebagai upaya mengejar atau mendekati warna tradisional biru nila dari iket kepala masyarakat Baduy sebagai simbolisasi kesan buhun atau kerakyatan. Dengan demikan tampilan Rawayan pada era ini secara keseluruhan memberikan kesan estetika semi modern (tradisional-moderen).

Kostum Jaipongan tahun 2000-2010 termasuk kostum era kreasi baru (moderen). Tampilan kostum Jaipongan pada masa ini berkembang semakin variatif. Penyebabnya banyak muncul penata kostum yang melahirkan gaya dan tampilan kostum baru dalam genre Jaipongan. Kostum
Jaipongan akhirnya mengalami pergeseran dan perkembangan yang sangat signifikan Dampaknya, kostum Jaipongan tampil semakin ekspresif terlihat dari bentuk kostum yang menjadi lebih bervariatif sebagai upaya menyesuaikan dengan tuntutan koreografi gerak tari dan tuntutan selera masyarakatnya. Kostum Jaipongan pada era ini dibuat dengan lebih mempertimbangkan aspek estetis hingga terkadang dinilai terlalu fashionable bagi sebuah tampilan kostum tari Sunda khususnya. Dengan demikian tampilan kostumnya dinyatakan bernilai estetika moderen.

Pada dasarnya bentuk silhouette line kostum atasan pada semua era seluruhnya tampil dalam konstruksi silhouette fitted. Hal ini dikarenakan konstruksi kostum atasan Jaipongan baik kebaya Sunda, baju senam (tayet) maupun apok sebagai luarannya cenderung body fit sehingga memperlihatkan conturing bentuk tubuh penarinya terutama bagian dada, pinggang dan panggul. Konstruksi body fit ini tidak lain bertujuan memberikan kesan slim atau langsing bagi penarinya.

Untuk bentuk silhouette line kostum bawahan sendiri terlihat mengalami pergeseran yang signifikan yakni diawali pada saat era tradisional tahun 1980 dimana bentuk silhouette line kostum bawahan tampil dalam bentuk siluet slim, bergeser menjadi bentuk siluet $A$-line (dipelopori oleh tampilan kostum Rawayan), yang kemudian baru memasuki era kreasi baru/moderen bentuk siluet kostum bawahan bergeser menjadi fit and flare line.

Adapun untuk konstruksi bentuk potongan silhouette yang mana terbentuk atas penggabungan silhouette line kostum atasan dengan kostum bawahan pun mengalami pergeseran bentuk. Adapun pergeseran bentuk potongan silhouette diawali pada era tradisional dengan bentuk potongan silhouette berupa amphora silhouette, bergeser pada era semi moderen berbentuk potongan si- 
lhouette hourglass, kemudian pada era moderen berbentuk silhouette hourglass, redingote silhouette, dan terakhir ekstra redingote silhouette.

\section{Daftar Pustaka}

Bing, Agus, dkk.

2009 "Kesima Busana dan Rias". Jurnal Gong - Majalah Seni Budaya. Edisi 15/x/2009. h.27-41. Yogyakarta: Yayasan Tikar Media Budaya Nusantara.

Caturwati, Endang, dkk.

1997 Rias Dan Busana Tari Sunda. Bandung: STSI Press.

Djelantik, A.A.M.

1990 Pengantar Dasar Ilmu estetika Jilid I

- Estetika Instrumental. Denpasar: Sekolah Tinggi Seni Indonesia (STSI).

1991 Estetika Sebuah Penghantar. Bandung: Masyarakat Seni Pertunjukan Indonesia.

Esmod

1995 Metode Menggambar Mode - Fashion Drawing Method. Jakarta: Esmod Edition.

Herdiani, Een

2008 “Tari Jaipongan Keser Bojong (Kajian Struktur dan Nilai Pada Tari Keseng Bojong Karya Gugum Gumbira)". Laporan Penelitian. Bandung: Sekolah Tinggi Seni Indonesia.
Mulyana, Edi

2009 "Gugum Gumbira dan Jaipongan Kajian Proses Kreatif". Tesis Program Studi Pengkajian Seni Minat Tari Nusantara. Surakarta: Pascacasarjana Institut Seni Indonesia (ISI).

Riyanto, Arifah A.

2003 Desain Busana. Bandung: Yapemdo.

Stone, Elaine

2006 The Dynamic Of Fashion. New York: Fairchilld.

Sudiarti, Tuti

2008 “Kajian Estetik Busana Kebesaran Sultan Kasepuhan, Kanoman dan Kacirebonan". Tesis Program Studi Magister Desain Fakultas Seni Rupa dan Desain. Bandung: Pascasarjana Institut Teknologi Bandung (ITB).

Suryahadi, Aak

1987 Dasar-Dasar Desain Busana. Jakarta: Depdikbud.

Takamura, Zeshu

1993 Ladie's Fashion Items - Fashion With Style. Tokyo-Japan: Graphic-sha Publishing Co.

Wardojo, Soejanto Poespo

1986 Pengertian Lokal Jenius Dan Relevansinya dalam Modernisasi, dalam Ayat Rohaedi, Kepribadian Budaya Bangsa (Lokal Genius). Jakarta: Pustaka Jaya. 